\title{
RESEARCH
}

Open Access

\section{Actigraphic measurement of the upper limbs movements in acute stroke patients}

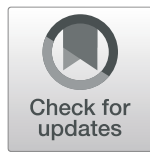

Chiara lacovelli', Pietro Caliandro ${ }^{2^{*}}$ (D), Marco Rabuffetti ${ }^{1}$, Luca Padua ${ }^{1,3}$, Chiara Simbolotti ${ }^{1}$, Giuseppe Reale $^{4}$, Maurizio Ferrarin ${ }^{1}$ and Paolo Maria Rossini ${ }^{4}$

\begin{abstract}
Background: Stroke units provide patients with a multiparametric monitoring of vital functions, while no instruments are actually available for a continuous monitoring of patients motor performance. Our aim was to develop an actigraphic index able both to identify the paretic limb and continuously monitor the motor performance of stroke patients in the stroke unit environment.
\end{abstract}

Methods: Twenty consecutive acute stroke patients (mean age 69.2 years SD 10.1, 8 males and 12 females) and 17 bed-restrained patients (mean age 70.5 years SD 7.3, 7 males and 10 females) hospitalized for orthopedic diseases of the lower limbs, but not experiencing neurological symptoms, were enrolled. This last group represented our control group. The motor activity of arms was recorded for $24 \mathrm{~h}$ using two programmable actigraphic systems showing off as wrist-worn watches. The firmware segmented the acquisition in epochs of 1 minute and for each epoch calculates two motor activity indices: $\mathrm{MA}_{\mathrm{e} 1}$ (Epoch-related Motor Activity index) and $\mathrm{MA}_{\mathrm{e} 2}$ (Epoch-related Motor Activity index 2). $M A_{e 1}$ is defined as the standard deviation of the acceleration module and $M A_{e 2}$ as the module of the standard deviation of acceleration components. To describe the $24 \mathrm{~h}$ motor performance of each limb, we calculated the mean value of $M A_{e 1}$ and $M A_{e 2}$ (respectively $M A_{1 \_24 h}$ and $M A_{2} 24 h$ ). Then we obtained two Asymmetry Rate Indices: $A R_{1 \_24 h}$ and $A R_{2 \_24 h}$ to show the motor activity prevalence. $A R_{1 \_24 h}$ refers to the asymmetry index between the values of $\mathrm{MA}_{\mathrm{e} 1}$ of both arms and $\mathrm{AR}_{2 \_24 h}$ to $\mathrm{MA}_{\mathrm{e} 2}$ values.

The stroke patients were clinically evaluated by NIHSS at the beginning $\left(\mathrm{NIHSS}_{T_{0}}\right)$ and at the end $\left(\mathrm{NIHSS}_{\mathrm{T}_{1}}\right)$ of the $24 \mathrm{~h}$ actigraphic recordings.

Results: Both $\mathrm{MA}_{1 \_24 \mathrm{~h}}$ and $\mathrm{MA}_{2 \_24 \mathrm{~h}}$ indices were smaller in the paretic than in the unaffected arm (respectively $p=0.004$ and $p=0.004$ ). $A R_{2 \_24 h}$ showed a better capability (95\% of paretic arms correctly identified, Phi Coefficient: 0.903 ) to discriminate the laterality of the clinical deficit than $\mathrm{AR}_{1} 24 \mathrm{~h}$ (85\% of paretic arms correctly identified, Phi Coefficient: 0,698). We also found that $A R_{1} 24 \mathrm{~h}$ did not differ between the two groups of patients while $A R_{2 \_24 h}$ was greater in stroke patients than in controls and positively correlated with NIHSS total scores (r: 0.714, $p<0.001$ for NIHSS, IC95\%: 0.42-0.90) and with the sub-score relative to the paretic upper limb (r: 0.812, $p<0.001$, IC95\%: 0.62-0.96).

Conclusions: Our data show that actigraphic monitoring of upper limbs can detect the laterality of the motor deficit and measure the clinical severity. These findings suggest that the above described actigraphic system could implement the existing multiparametric monitoring in stroke units.

Keywords: Actigraphy, Disability motor evaluation, Multiparametric monitoring, Stroke, Innovative biotechnologies

\footnotetext{
*Correspondence: pietro.caliandro@policlinicogemelli.it

${ }^{2}$ Complex Operative Unit of Neurology, Fondazione Policlinico Universitario

A. Gemelli IRCSS, L.go F. Vito, 1, 00168 Rome, Italy

Full list of author information is available at the end of the article
}

(c) The Author(s). 2019 Open Access This article is distributed under the terms of the Creative Commons Attribution 4.0 International License (http://creativecommons.org/licenses/by/4.0/), which permits unrestricted use, distribution, and reproduction in any medium, provided you give appropriate credit to the original author(s) and the source, provide a link to the Creative Commons license, and indicate if changes were made. The Creative Commons Public Domain Dedication waiver (http://creativecommons.org/publicdomain/zero/1.0/) applies to the data made available in this article, unless otherwise stated. 


\section{Background}

Stroke is a disease with a high social impact causing high mortality and severe residual disability. In particular, during the acute phase it is difficult to assess the patient's functional prognosis, especially with regard to the motor deficits that impair the activity in daily life [1, 2]. After a stroke, hemiparesis is the most common residual disability with a wide range of severity, having the upper limb the lowest functional recovery [3-5]. During the acute phase, tracking the motor performance variations of the affected upper limb versus the unaffected arm could be useful to measure clinical severity over time and to formulate a prognosis. Nowadays, the stroke unit represents the gold standard in the management of the acute stroke, since it provides a continuous multi-parametric monitoring that allows the identification of changes in cardiac functioning, blood pressure levels and hematic oxygen saturation. At the moment, the continuous monitoring of motor deficit is not implemented in the stroke unit environment. Actigraphy allows the long-term assessment of the patient's wrist movements by means of a small solid-state sensor. Several applications of actigraphy based on accelerometers have been proposed. Indeed, actigraphy has proved its usefulness not only in sleep medicine [6], but also in other fields, for example in Parkinson tremor quantification [7]. So far, few papers have reported the use of actigraphy in stroke: these studies provided the first indication that actigraphy might be sensitive enough to detect changes in motor activity during the recovery process and to quantify motor activity in everyday life [8-14] but, no data is available about the spontaneous upper limb motor performance in the very acute phase of stroke, when the instability of clinical picture can strongly impact on prognosis and future disability and the patient needs to be monitored in an intensive care unit. Page et al. [15] have used actigraphy to evaluate rehabilitative therapies in subacute stroke subjects. Gubbi et al. [16] performed short actigraphic recordings in the hyper-acute poststroke phase and developed an algorithm capable of calculating an index equivalent to the motor subscore of the National Institutes of Health Stroke Scale (NIHSS) that is a clinical score used to monitor changes of the neurological status during the hospital stay, with a maximum of 42 (severe stroke) and a minimum of 0 (no symptoms) [17]. The same group subsequently used that index to quantify the movement difference between arms by an intra-class correlation coefficient (ICC) analysis. They found that the greater is the difference in activity between the affected and unaffected limb, as measured by ICC, the higher is the NIHSS total score; however, they did not found any correlation between the inter-limbs motor difference and the more specific NIHSS motor sub-score [18]. Reiterer et al. actigraphically monitored motor activity of both arms in 38 patients with transient ischemic attack, ischemic lesion or nontraumatic intracerebral haemorrhage for $24 \mathrm{~h}$ in four different time points: $24-36 \mathrm{~h}$ after symptoms onset, 5-7 days later, at 3 and 6 months after symptoms onset. They demonstrated that motor performance of paretic and not paretic limbs differ during the first two time points while in the further two time points this difference was attenuated [19]. However, the actigraphic index used by the Authors did not correlate with the clinical severity in the acute phase as assessed by the NIHSS. Moreover, the Authors performed $24 \mathrm{~h}$ recordings in a very heterogeneous sample of patients (transient ischemic attack, ischemic lesion and non-traumatic intracerebral hemorrhage), therefore the reported data cannot be considered as representative of the ischemic stroke scenario. Urbin et al. investigated different metrics to measure upper limb motor performance in subacute and chronic ischemic and hemorrhagic stroke patients during motor training and in a free-living environment. They described the asymmetry of motor performance between paretic and non-paretic arm as a ratio between the variability of the paretic arm acceleration relative to variability of the nonparetic arm. They found that the asymmetry correlates with upper extremity function during the rehabilitative process and in a free-living environment $[9,10]$. Since the authors enrolled ischemic and hemorrhagic, subacute and chronic stroke patients in an environment very different from that of a stroke unit, their results, although useful to evaluate the efficacy of different parameters, cannot be considered representative of the clinical picture of ischemic stroke patients who require intensive cares in their very acute phase.

In a previous study performed in healthy subjects, Rabuffetti et al. defined a novel numerical index to quantify upper limb motor activity and the between-limb motor asymmetry. The proposed motor activity index only depends on sensor position and not on sensor orientation (i.e. indices invariant to sensor orientation), therefore it could represent a robust approach to monitor spontaneous motor performance in complex environments such as stroke units. Moreover, the proposed asymmetry index is based on epoch-based asymmetry and not on average overall asymmetry $[9,10]$ therefore it could be theoretically very precise in describing motor performance over time [20]. We hypothesized that such index might effectively track the motor behavior of bed-restrained patients and could be useful to implement the multiparametric monitoring in the stroke unit environment. Therefore the aims of the present study were: 
- to verify if the actigraphic asymmetry index, as calculated by Rabuffetti, can identify the paretic arm of acute stroke patients;

- to verify if such asymmetry index can properly quantify the clinical severity of acute stroke patients in the very particular environment of a stroke unit.

\section{Methods}

\section{Population}

Twenty consecutive middle cerebral artery stroke patients (mean age 69.2 years SD 10.1, 8 males and 12 females) were enrolled in the acute phase of stroke $(3.3 \pm 1.6$ days after stroke onset) regardless the side, location, extension of the ischemic lesion and clinical severity. We enrolled as control group 17 patients (mean age 70.4 years SD 4.8, 7 males and 10 females) who were hospitalized for orthopedic diseases of the lower limbs, bed-restrained but not experiencing neurological symptoms. The exclusion criteria were previous ischemic stroke, hemorrhagic stroke, diagnosis of epilepsy and/or cognitive impairment, anamnestic and/or instrumental evidence of previous upper limb motor impairment. The patients were clinically evaluated by NIHSS at the beginning $\left(\mathrm{NIHSS}_{\mathrm{TO}}\right)$ and at the end $\left(\mathrm{NIHSS}_{\mathrm{T} 1}\right)$ of the $24 \mathrm{~h}$ actigraphic recordings. When the NIHSS motor sub-score of the controlesional upper limb was scored as zero we had evaluated the presence of hand pronation as sign of clinical impairment. We coded the onset lesion load by the ASPECT score [21]. All participants were right-handed as assessed by the Edinburgh questionnaire [22]. The research was approved by the local ethics committee (Fondazione Policlinico Universitario A. Gemelli, Prot N. 0007987/17) and complies with the Helsinki Declaration. Informed written consent was obtained.

\section{Actigraphic recordings and data processing}

The motor activity of both arms was recorded for 24 hours using two programmable actigraphic systems (EZ430-Chronos, Texas Instruments, Dallas, TX, USA) showing off as wrist-worn watches. The two devices (one for each wrist) were synchronized in order to obtain in the same time points the recordings of both limbs. The EZ430-Chronos is equipped with $4 \mathrm{kB}$ RAM and $32 \mathrm{kB}$ flash memory, a solid-state 3 -axial sensor based on MEMS technology measuring acceleration at $33 \mathrm{~Hz}$ sampling rate, with a 10-bit resolution over a $4 \mathrm{~g}$ full scale. In real-time, the EZ430-Chronos compute the modulus of the acceleration.

The firmware, integrated in each device, segmented the acquisition in epochs of 1 minute and for each epoch calculates a motor activity index $\mathrm{MA}_{\mathrm{e} 1}$ (Epoch-related
Motor Activity index) as the standard deviation $(\sigma)$ of the acceleration module:

$$
M A_{e 1}=\sigma_{\bar{a}} \cdot \text { where } \bar{a}=\sqrt{a_{x}^{2}+a_{y}^{2}+a_{z}^{2}}
$$

In the formula $\mathrm{a}_{\mathrm{x}}{ }^{2}, \mathrm{a}_{\mathrm{y}}{ }^{2}$, and $\mathrm{a}_{\mathrm{z}}{ }^{2}$ represents the acceleration components in the three axis [20]. Additionally, a second motor index $\mathrm{MA}_{\mathrm{e} 2}$ is computed, in the same epochs of the first index, according to the following formula

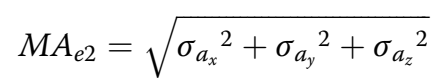

Where $\sigma \mathrm{a}_{\mathrm{x}}{ }^{2}, \sigma \mathrm{a}_{\mathrm{y}}{ }^{2}$ and $\sigma \mathrm{a}_{\mathrm{z}}{ }^{2}$ are the standard deviations of the acceleration components in the three axis. In this case $\mathrm{MA}_{\mathrm{e} 2}$ is defined as the module of the standard deviation of acceleration components.

Since gravity, a constant vector entity, determines measurable acceleration components according to the orientation of the triaxial sensor, it can be expected that a pure rotation of the wrist (or, more precisely, a pure rotation of the triaxial sensor fixed onto the wrist) modulate the measured acceleration components along the three sensor axes. According to this observation, a pure wrist rotation without a linear acceleration (for example the forearm pronation-supination typically occurring in a bed restrained patient) implies a non-zero value for the second index $\mathrm{MA}_{\mathrm{e} 2}$ while $\mathrm{MA}_{\mathrm{e} 1}$ returns a null value. On the contrary, a pure linear acceleration is reflected by non-zero values of both indices. When rotations and linear accelerations are combined, $\mathrm{MA}_{\mathrm{e} 1}$ is sensitive only to linear acceleration while $\mathrm{MA}_{\mathrm{e} 2}$ is determined by both components. However, since rotations imply a modulation of measured acceleration components up to $2 \mathrm{~g}$ (about $20 \mathrm{~m} / \mathrm{s}^{2}$ ), it is obvious that $\mathrm{MA}_{\mathrm{e} 2}$ is much more sensitive to sensor rotations and, therefore, $\mathrm{MA}_{\mathrm{e} 2}$ can be assumed as a monitor specific for sensor rotations.

To describe the $24 \mathrm{~h}$ motor performance of each limb, we calculated the mean value of $\mathrm{MA}_{\mathrm{e} 1}$ and $\mathrm{MA}_{\mathrm{e} 2}$ (respectively $\mathrm{MA}_{1 \_24 \mathrm{~h}}$ and $\mathrm{MA}_{2 \_24 \mathrm{~h}}$ ) being the distribution of values normal. Moreover, the $\mathrm{MA}_{\mathrm{e} 1}$ and $\mathrm{MA}_{\mathrm{e} 2}$ time profiles of the right and left limbs were used to quantify the asymmetry between the motor activities of the two sides over the $24 \mathrm{~h}$ recordings, adopting a previously described method [20]. For both $\mathrm{MA}_{\mathrm{e} 1}$ and $\mathrm{MA}_{\mathrm{e} 2}$ indices, the synchronous values of the right and left side were scatter plotted: the values of the right wrist on $\mathrm{x}$-axis and those of the left side on $y$-axis. Data points belonging to the quadrant bisecant indicate a strictly symmetric behavior, those in the inferior triangular area refer to epochs in which the motor activity was higher in the right side while those in the superior triangular area refer to epochs with a prevalence of left movements. 
The data cloud best-fitting line, passing through the axes origin and minimizing the sum of squared residuals, is the geometrical entity that summarize the asymmetry as occurred in the recordings. Such best-fitting line computationally corresponds to the first eigenvector as obtained by a singular value decomposition in a principal component analysis. Finally, after transforming, by the arctangent operator, the slope coefficient of the bestfitting line to the angle between the $\mathrm{x}$-axis and the eigenvector, the percent Asymmetry Rate Index for the $24 \mathrm{~h}$ period $\left(\mathrm{AR}_{24 \mathrm{~h}}\right)$ was defined as follows [20]:

$$
A R_{24 h}=100.0 \cdot \frac{45^{\circ}-\alpha}{45^{\circ}}
$$

The $\mathrm{AR}_{24 \mathrm{~h}}$ shows a null value in a symmetric behavior, positive values for a prevalence of right side motor activity (up to a maximum of $100 \%$ if the left activity is absent) and negative values for a left side motor activity prevalence (Fig. 1). In the following we will refer to the asymmetry index of the $\mathrm{MA}_{\mathrm{e} 1}$ index as $\mathrm{AR}_{1 \_24 \mathrm{~h}}$ and as $\mathrm{AR}_{2 \_24 \mathrm{~h}}$ for $\mathrm{MA}_{\mathrm{e} 2}$ index. Both asymmetry indices were calculated using MATLAB (The Mathworks, Natick, USA). It is noteworthy that nurses reported on a dedicated diary every moment in which the patient was passively mobilized and the asymmetry indices $\left(\mathrm{AR}_{1 \_24 \mathrm{~h}}\right.$ and as $\mathrm{AR}_{2 \_24 \mathrm{~h}}$ ) were calculated either after having removed those confounding intervals or considering them in the analysis of $\mathrm{MA}_{\mathrm{e} 1}$ and $\mathrm{MA}_{\mathrm{e} 2}$ indices.

\section{Statistical analysis}

All statistical analyses were performed in SPSS statistics software (version 20.0). The Shapiro-Wilk probability test was

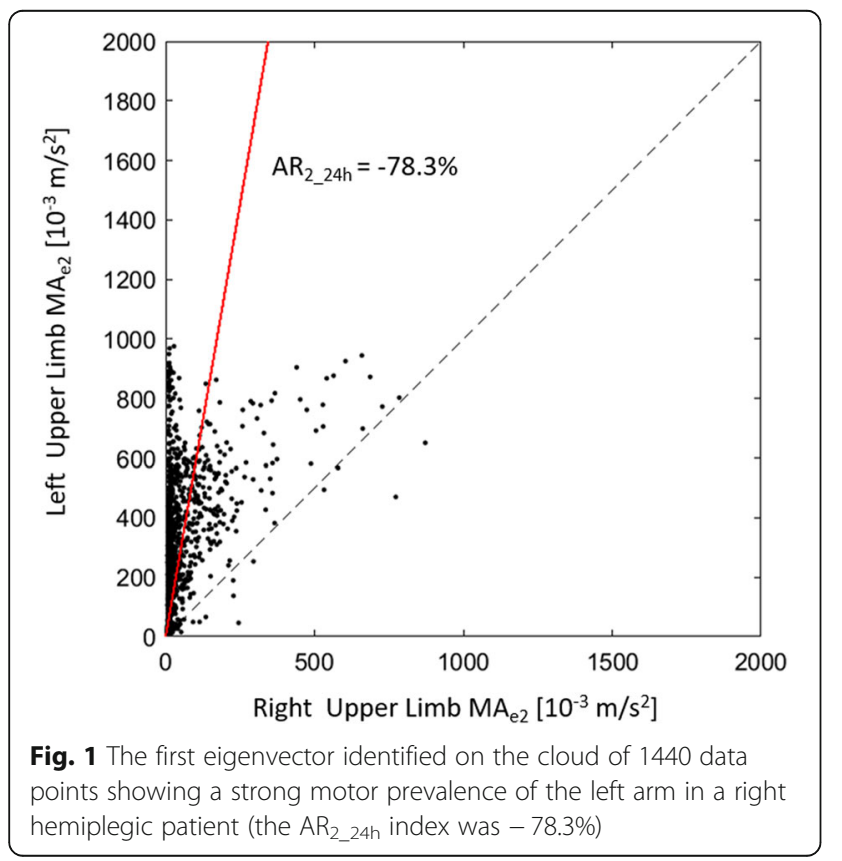

used to assess the normality of the distributions. We used the Wilcoxon non-parametric test to compare the values of $\mathrm{MA}_{124 \mathrm{~h}}$ and $\mathrm{MA}_{224 \mathrm{~h}}$ indices between the paretic and unaffected arms and to compare $\mathrm{NIHSS}_{\mathrm{T} 0}$ and $\mathrm{NIHSS}_{\mathrm{T1}}$ scores. We used the Mann-Whitney U Test to compare the asymmetry indices between controls and patients.

In order to evaluate the agreement between the deficit laterality measured by $\mathrm{AR}_{1 \_24 \mathrm{~h}}$ and $\mathrm{AR}_{2 \_24 \mathrm{~h}}$ and the clinically defined laterality, we used the Phi Coefficient. The Pearson's test was used to correlate the degree of asymmetry between arms as measured by the absolute value of $\mathrm{AR}_{1 \_24 \mathrm{~h}}$ and $\mathrm{AR}_{2 \_24 \mathrm{~h}}$ with NIHSS scores (either before or after having removed the epochs with passive movements). A $p<0.05$ was set as the level of significance.

\section{Results}

Table 1 shows clinical, demographic and actigraphic data of the enrolled stroke sample.

Table 2 shows clinical, demographic and actigraphic data of the enrolled control sample.

Figure 2 illustrates $\mathrm{MA}_{\mathrm{e} 1}$ and $\mathrm{MA}_{\mathrm{e} 2}$ profiles during the $24 \mathrm{~h}$ actigraphic monitoring in a paradigmatic patient with right hemiplegia: the blue line refers to the movement of the right wrist while the red profile to the left wrist. $\mathrm{MA}_{\mathrm{e} 1}$ shows very low values during the whole recording (Fig. 2a); on the opposite $\mathrm{MA}_{\mathrm{e} 2}$ shows greater values (Fig. $2 \mathrm{~b}$ ). Figure 3 shows the $\mathrm{MA}_{\mathrm{e} 2}$ profiles of two patients respectively with left (Fig. 3a) and right hemiplegia (Fig. 3b). $\mathrm{MA}_{\mathrm{e} 2}$ profiles show a clear prevalence of the right limb movement in the left hemiplegic patient $\left(\mathrm{AR}_{2 \_24 \mathrm{~h}}=+92.1 \%\right)$ (Fig. 3a) and vice versa a prevalence of the left movement in the patient with right hemiplegia $\left(\mathrm{AR}_{2 \_24 \mathrm{~h}}=-78.3 \%\right)$ (Fig. 3b). We found no difference between $\mathrm{NIHSS}_{\mathrm{T} 0}$ and $\mathrm{NIHSS}_{\mathrm{T1}}$ scores. Both $\mathrm{MA}_{1 \_24 \mathrm{~h}}$ and $\mathrm{MA}_{224 \mathrm{~h}}$ indices were smaller in the paretic than in the unaffected arm (respectively $p=0.004$ and $p=0.004$ ) (Fig. 4). We found that $\mathrm{AR}_{2} 24 \mathrm{~h}$ was greater in stroke patients than in controls, while $\mathrm{AR}_{1 \_24 \mathrm{~h}}$ did not differ between groups (Fig. 5). $\mathrm{AR}_{2 \_24 \mathrm{~h}}$ showed a better capability (95\% of paretic arms correctly identified, Phi Coefficient: 0.903) to discriminate the laterality of the clinical deficit than $\mathrm{AR}_{1 \_24 \mathrm{~h}}(85 \%$ of paretic arms correctly identified, Phi Coefficient: 0.698) (Table 3).

$\mathrm{AR}_{1 \_24 \mathrm{~h}}=$ Asymmetry Rate Index of the $\mathrm{MA}_{\mathrm{e}}$ index for the $24 \mathrm{~h}$ period,

$\mathrm{AR}_{2 \_24 \mathrm{~h}}=$ Asymmetry Rate Index of the $\mathrm{MA}_{\mathrm{e} 2}$ index for the $24 \mathrm{~h}$ period.

Moreover, we found a positive correlation between $\mathrm{AR}_{2 \_24 \mathrm{~h}}$ and NIHSS total scores ( $\mathrm{r}: 0.714, p<0.001$ for $\mathrm{NIHSS}_{\mathrm{T} 1}$, CI95\%: 0.42-0.90) and between $\mathrm{AR}_{2 \_24 \mathrm{~h}}$ and the sub-score relative to the paretic upper limb (r: 0.812, $p<0.001$ for $\mathrm{T} 1$ sub score, CI95\%: $0.62-$ 0.96) (Fig. 6). The correlation between $\mathrm{AR}_{2} 24 \mathrm{~h}$ and the NIHSS scores worse when the epochs related to 


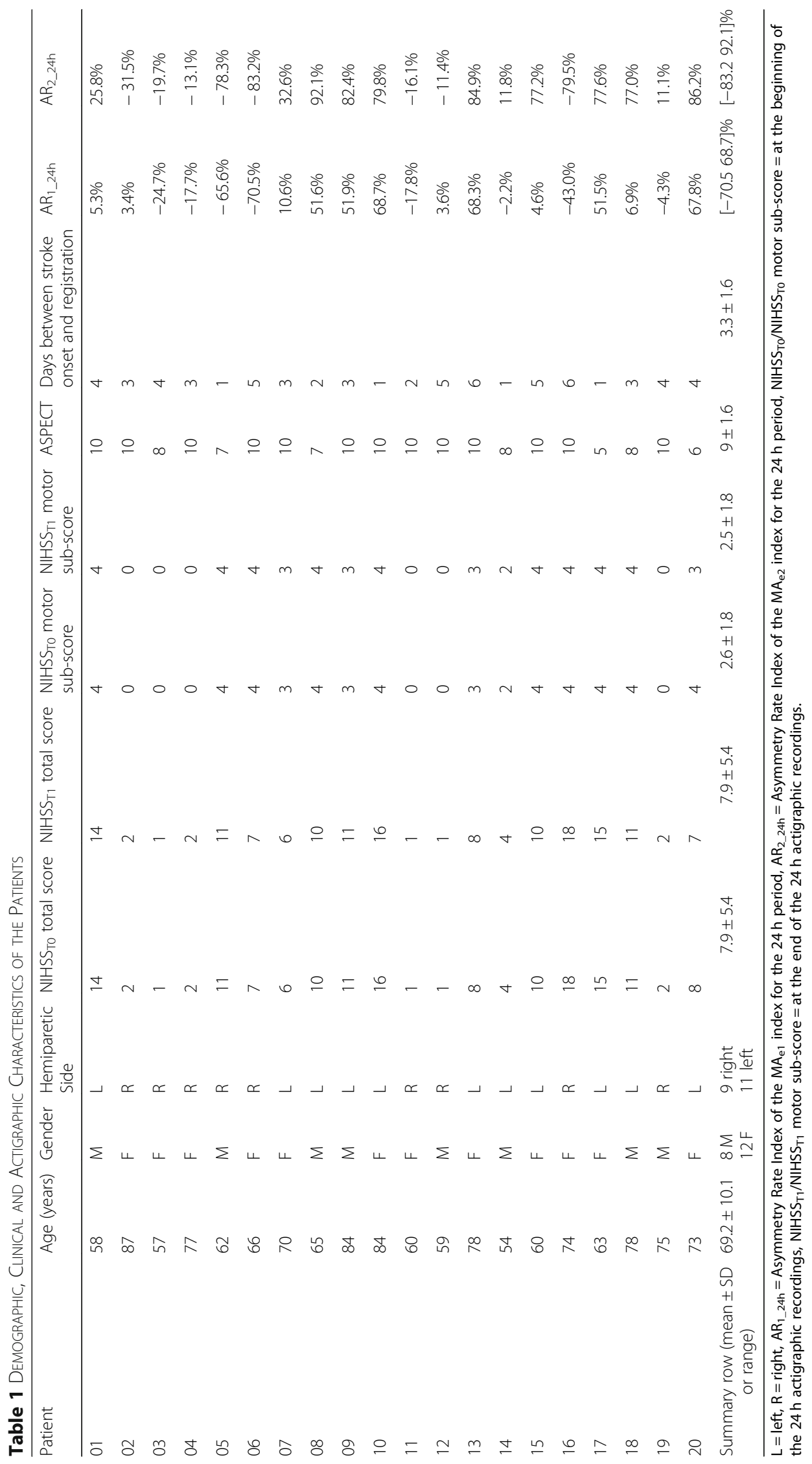


Table 2 Demographic, Clinical and Actigraphic Characteristics of the Controls

\begin{tabular}{|c|c|c|c|c|c|}
\hline Control & Age (years) & Gender & Orthopedic intervention & $\mathrm{AR}_{1 \_24 \mathrm{~h}}$ & $A R_{2 \_24 h}$ \\
\hline 01 & 65 & M & hip replacement & $-26.3 \%$ & $-1.2 \%$ \\
\hline 02 & 72 & $\mathrm{~F}$ & knee replacement & $24.8 \%$ & $20.2 \%$ \\
\hline 03 & 68 & $\mathrm{~F}$ & knee replacement & $-19.7 \%$ & $-13.4 \%$ \\
\hline 04 & 77 & $\mathrm{~F}$ & hip replacement & $31.9 \%$ & $10.9 \%$ \\
\hline 05 & 68 & M & hip replacement & $-0.8 \%$ & $-1.7 \%$ \\
\hline 06 & 71 & $\mathrm{~F}$ & knee replacement & $44.6 \%$ & $-10.8 \%$ \\
\hline 07 & 69 & F & hip replacement & $-0.1 \%$ & $-14.0 \%$ \\
\hline 08 & 62 & M & hip replacement & $-22.1 \%$ & $0.1 \%$ \\
\hline 09 & 71 & M & hip replacement & $-39.2 \%$ & $-21.1 \%$ \\
\hline 10 & 75 & $\mathrm{~F}$ & hip replacement & $4.4 \%$ & $-0.4 \%$ \\
\hline 11 & 60 & F & knee replacement & $3.1 \%$ & $4.6 \%$ \\
\hline 12 & 75 & M & hip replacement & $1.7 \%$ & $-16.5 \%$ \\
\hline 13 & 75 & F & hip replacement & $2.6 \%$ & $-10.8 \%$ \\
\hline 14 & 70 & M & knee replacement & $20.3 \%$ & $18.8 \%$ \\
\hline 15 & 74 & F & hip replacement & $30.5 \%$ & $8.3 \%$ \\
\hline 16 & 74 & M & hip replacement & $-6.8 \%$ & $-3.9 \%$ \\
\hline 17 & 71 & F & knee replacement & $2.6 \%$ & $11.3 \%$ \\
\hline $\begin{array}{l}\text { Summary row } \\
\text { (mean } \pm \text { SD or range) }\end{array}$ & $70.4 \pm 4.8$ & $\begin{array}{l}7 \mathrm{M} \\
10 \mathrm{~F}\end{array}$ & $\begin{array}{l}11 \text { hip replacement } \\
6 \text { knee replacement }\end{array}$ & {$[-39.244 .6] \%$} & {$\left[\begin{array}{lll}-21.1 & 20.2] \%\end{array}\right.$} \\
\hline
\end{tabular}

$\mathrm{AR}_{1 \_24 \mathrm{~h}}=$ Asymmetry Rate Index of the $\mathrm{MA}_{\mathrm{e} 1}$ index for the $24 \mathrm{~h}$ period, $\mathrm{AR}_{2 \_24 \mathrm{~h}}=$ Asymmetry Rate Index of the $\mathrm{MA}_{\mathrm{e} 2}$ index for the $24 \mathrm{~h}$ period.

passive movements were not rejected (correlation between $\mathrm{AR}_{224 \mathrm{~h}}$ and $\mathrm{NIHSS}_{\mathrm{T} 1}$ was $\mathrm{r}: 0.408, p: 0.074$, CI95\%: 0.03-0.73; between $\mathrm{AR}_{2} 24 \mathrm{~h}$ and NIHSS subscore relative to the paretic upper limb at $\mathrm{T} 1 \mathrm{r}$ : 0.546, $p$ : 0.01, C195\%: 0.23-0.79).

\section{Discussion}

Our data show that actigraphic monitoring of upper limbs spontaneous movements is able to distinguish the paretic arm from the healthy one. We have tested two different indices, namely $\mathrm{MA}_{\mathrm{e} 1}$ and $\mathrm{MA}_{\mathrm{e} 2}$, documenting

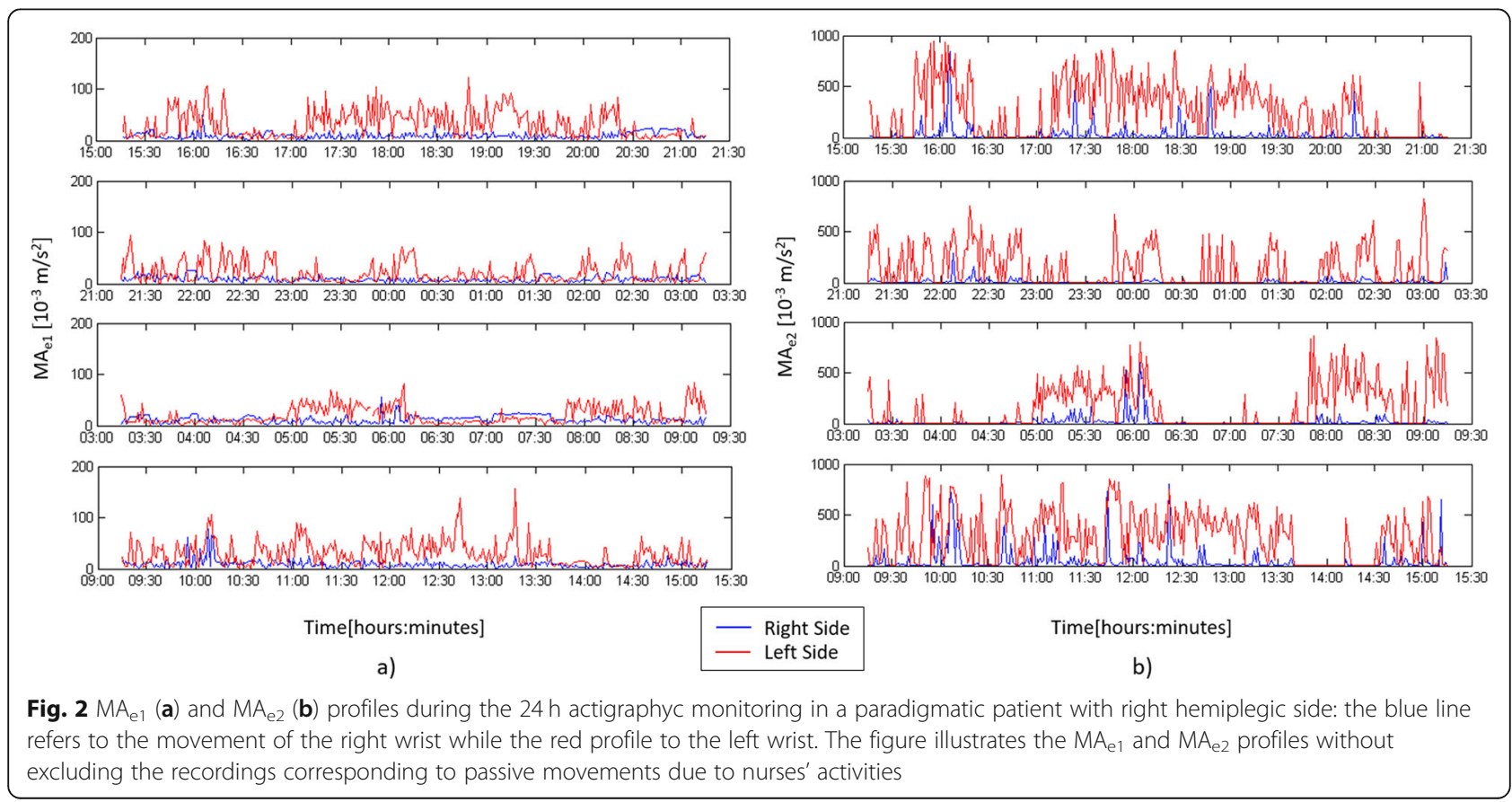




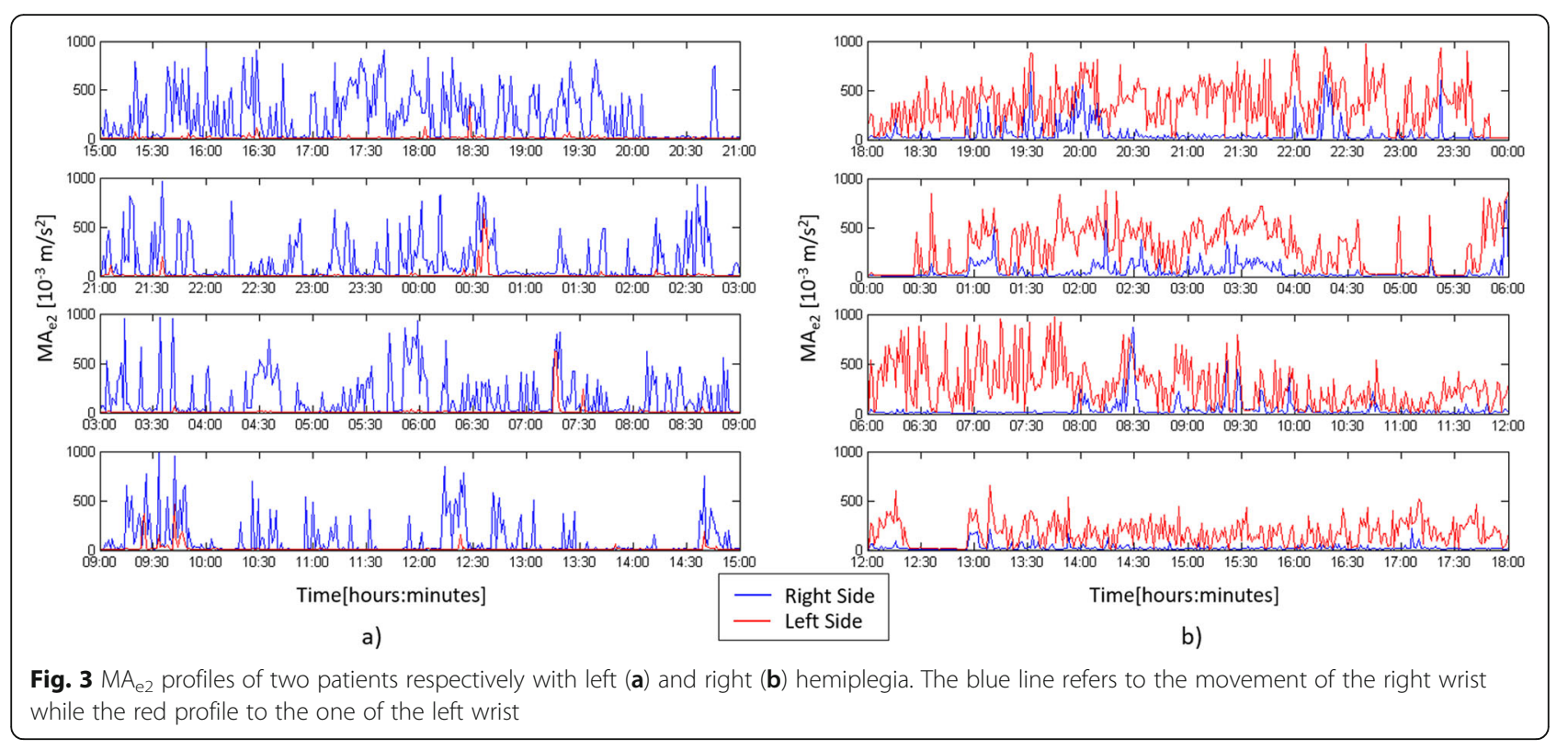

a statistically greater motor activity in the healthy side. However, when the asymmetry indices $A_{1} R_{1} 24 \mathrm{~h}$ and $\mathrm{AR}_{2 \_24 \mathrm{~h}}$ (respectively based on $\mathrm{MA}_{\mathrm{e} 1}$ and $\mathrm{MA}_{\mathrm{e} 2}$ ) were used to describe the motor performance of the affected arm relatively to the performance of the unaffected one, the two asymmetry indices present different patterns. On the one hand, the $\mathrm{AR}_{2 \_24 \mathrm{~h}}$ shows a greater asymmetry in stroke patients than in the control group, it is informative about the severity of the neurological symptoms (strong correlation with the NIHSS upper-limb score and with the NIHSS total score) and predictive of the laterality of the clinical impairment. On the other hand, $\mathrm{AR}_{1 \_24 \mathrm{~h}}$ does not allow to distinguish stroke patients from bed-restrained subjects without motor impairment of upper limbs. Indeed $A_{1 \_24 h}$ does not differ between stroke patients and control group. Technically, the main difference between $\mathrm{AR}_{1 \_24 \mathrm{~h}}$ and $\mathrm{AR}_{2 \_24 \mathrm{~h}}$ consists in the different way in which $\mathrm{MA}_{\mathrm{e} 1}$ and $\mathrm{MA}_{\mathrm{e} 2}$ are computed, being $\mathrm{MA}_{\mathrm{e} 2}$ based on the evaluation of each component of the acceleration and $\mathrm{MA}_{\mathrm{e} 1}$ on the variation of the module of acceleration [20]. This element is pivotal in determining a higher capability of $\mathrm{AR}_{2 \_24 \mathrm{~h}}$ to describe the motor performance in our sample of patients who may experience a severe limitation of the movement: the $\mathrm{MA}_{\mathrm{e} 2}$ definition, contrarily to the $\mathrm{MA}_{\mathrm{e} 1}$ one, is able to detect sensor rotations, i.e. forearm pronosupination in the considered bedridden patients [20]. It is noteworthy that the $\mathrm{AR}_{2} 24 \mathrm{~h}$ was able to identify a right slight motor deficit $\left(\mathrm{AR}_{2 \_24 \mathrm{~h}}\right.$ ranges from $11.4 \%$ to $-31.5 \%$ ) even in five out of the six patients

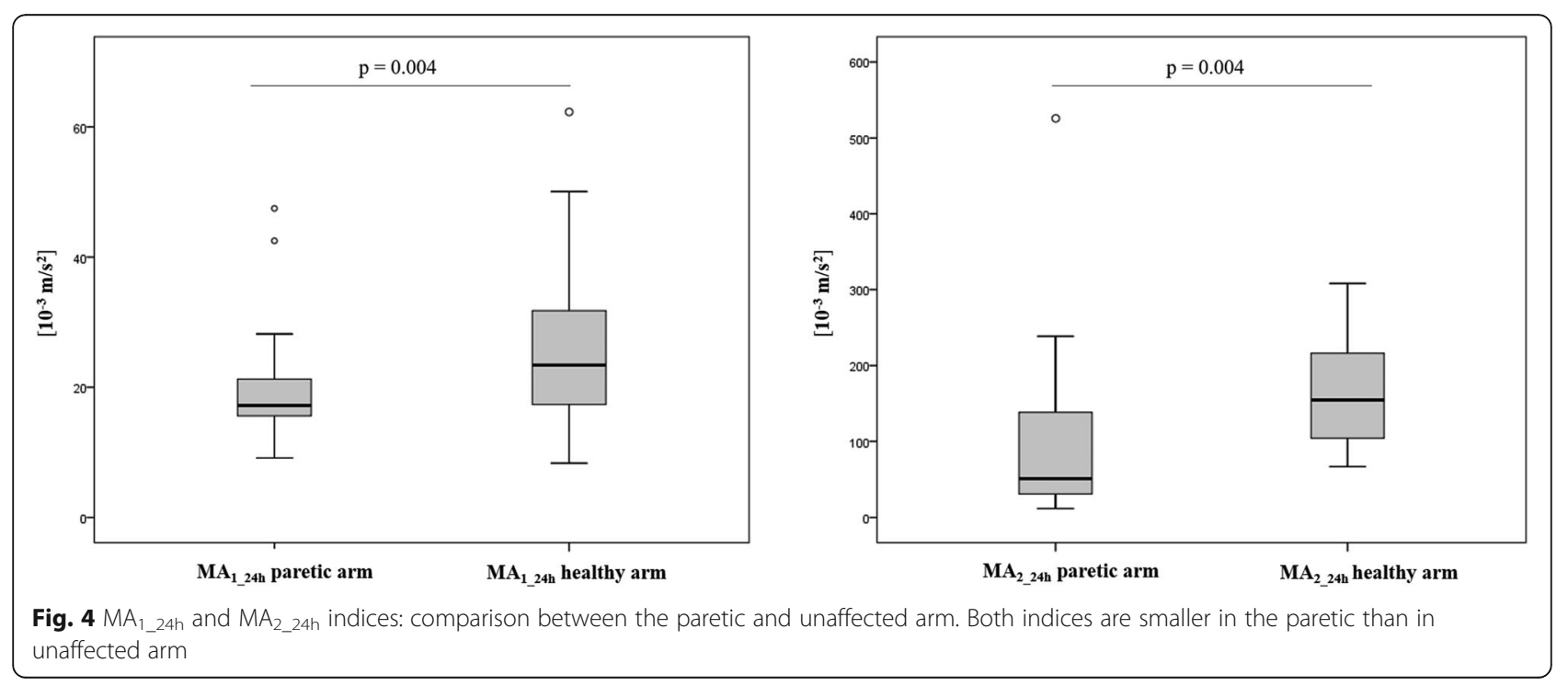




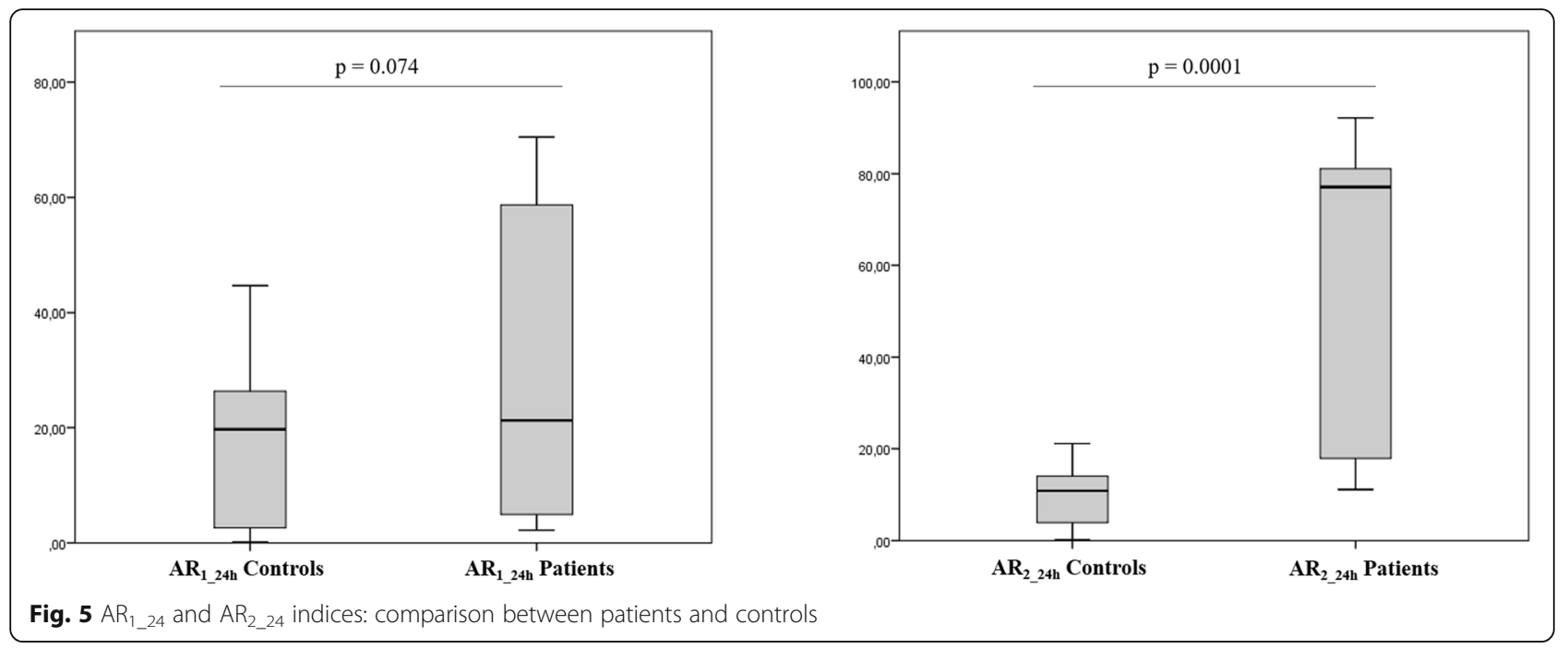

with left hemispheric stroke and whose clinical scores failed to show a motor deficit (the five patients presented hand pronation but a NIHSS arm subscore $=0$ meaning absence of arm drift). In one patient with left hemispheric stroke and NIHSS arm subscore $=0$, $\mathrm{AR}_{2 \_24 \mathrm{~h}}$ shows a slight motor prevalence of the right arm (patient 19 in Table $1, \mathrm{AR}_{2 \_24 \mathrm{~h}}:+11.1 \%$ ) revealing no right motor deficit: this apparently contradictory result is simply explained by the absence of a motor deficit of the right upper limb (no hand pronation) and the presence of a physiological motor prevalence of the dominant (right) side, as observed in healthy subjects $[23,24]$.

Gebruers and colleagues performed a study similar to ours in acute stroke patients and highlighted that actigraphic measurements show moderate correlation with NIHSS total score [25] and can contribute to predict clinical recovery as measured by Fugl-Meyer and modified Rankin scale [26, 27] More deeply, the actigraphic recordings of the paretic arm correlated better with NIHSS total score than the ratio between the activities of the two arms. Moreover they found that the NIHSS sub-score relative to the paretic upper limb was related with actigraphic variables only in patients with left hemispheric lesions. The moderate correlation between the actigraphic recordings and the clinical picture is probably explained by the method adopted to analyze the actigraphic findings. The authors used the Proportional Integrating Measure (PIM), a modality of movement measurement consisting in integrating the signal from the sensor to calculate the area under the rectified curve. This area was calculated for the affected and the unaffected upper arms and presented as an amount of activity. Ratio was calculated by dividing the area under the rectified curve of the affected upper limb by the area under the curve of the unaffected side. Therefore the parameters described represent an overall evaluation of movement over the $24 \mathrm{~h}$ without considering the time profile of changes of motor activity. In our approach we calculated the asymmetry index not as a simple ratio between the overall motor activities of the two sides but we considered the time profiles of $\mathrm{MA}_{\mathrm{e} 1}$ and $\mathrm{MA}_{\mathrm{e} 2}$ in both arms to identify the eigenvectors which represent the data cloud best-fitting line. Then the asymmetry indices were computed by measuring the angle between the $\mathrm{x}$ axes and the eigenvectors. In this way the asymmetry indices describe the asymmetry between synchronous values related to the movement of the two limbs and independently by knowing which was the paretic side. It is remarkable that we did not select our patients according to the clinical picture and therefore we also enrolled patients scored as zero to the NIHSS upper limb sub-score. This choice could reduce the capability of asymmetry indices to discriminate between affected and unaffected limb but our results demonstrate that the $\mathrm{AR}_{2 \_24 \mathrm{~h}}$ index has an excellent capability to discriminate the laterality of the clinical deficit and a very good correlation with NIHSS total score

Table 3 Deficit LATERALITY AS DESCRIBED BY AR 1 24H AND AR 2 24H

\begin{tabular}{|c|c|c|c|c|c|c|}
\hline & \multicolumn{3}{|c|}{ Hemiparetic Side as assessed by $A R_{1} \_24 h$} & \multicolumn{3}{|c|}{ Hemiparetic Side as assessed by $\mathrm{AR}_{2 \_24 \mathrm{~h}}$} \\
\hline & Right & Left & Total & Right & Left & Total \\
\hline Right Hemiparesis & 7 & 2 & 9 & 8 & 1 & 9 \\
\hline Left Hemiparesis & 1 & 10 & 11 & 0 & 11 & 11 \\
\hline Total & 8 & 12 & 20 & 8 & 12 & 20 \\
\hline
\end{tabular}



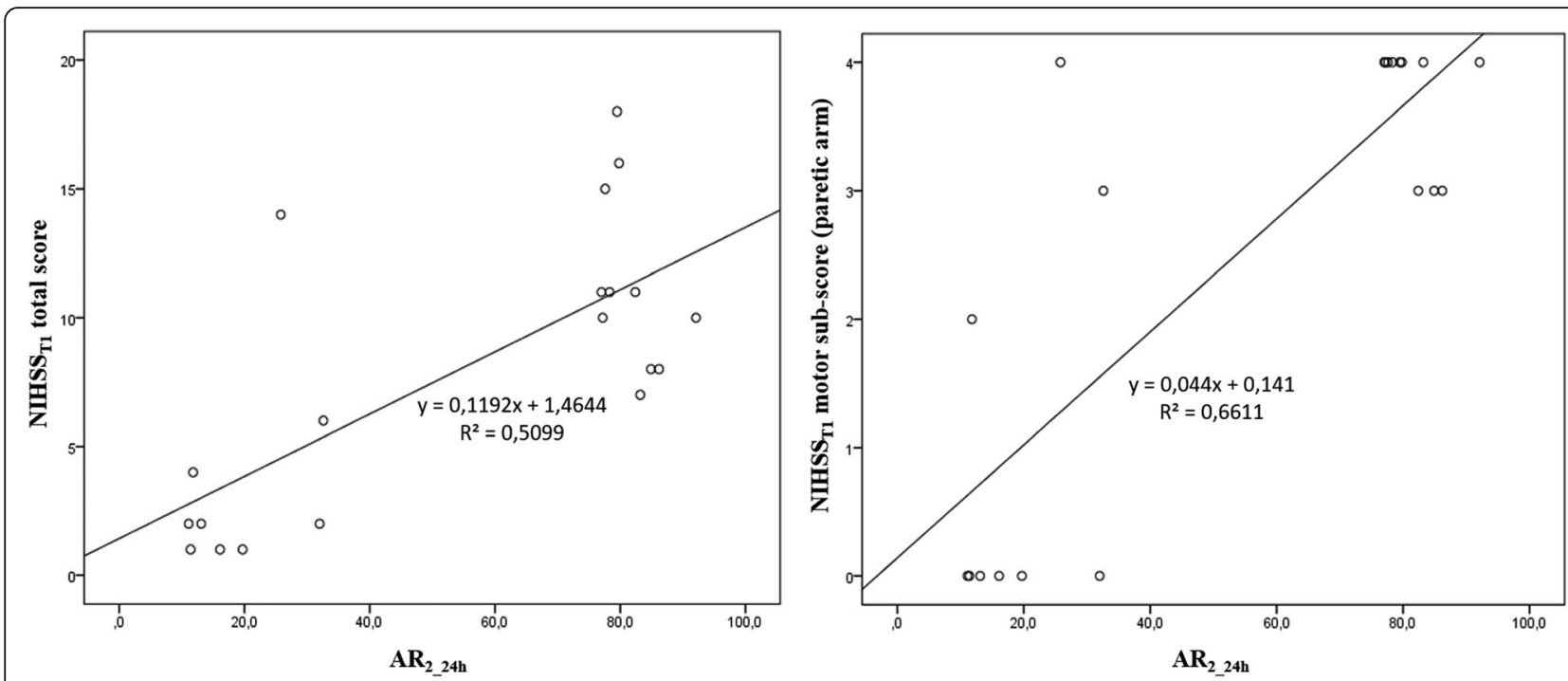

Fig. 6 Correlation between $A R_{2 \_24 h}$ and $\mathrm{NIHSS}_{T 1}$ total scores and between $A R_{2 \_24 h}$ and $\mathrm{NIHSS}_{\mathrm{T} 1}$ sub-score relative to the paretic upper limb

and the sub-score relative to the paretic side [25]. Our approach in measuring motor asymmetry by the $\mathrm{MA}_{\mathrm{e} 1}$ index was conceptually similar but not equal to that adopted by Urbin and colleagues in a sample of subacute/chronic ischemic and hemorrhagic stroke patients during the rehabilitation process or in an everyday free-living environment $[9,10]$. From an engineering perspective, a first difference consists in calculating $\mathrm{MA}_{\mathrm{e} 1}$ index without removing epochs where no acceleration occurred. In fact, in our environment (stroke unit with acute patients monitored at bed) no acceleration could indicate plegia of the arm therefore, removing those epochs would have meant removing a clinical crucial information. Urbin and colleagues made a different choice because their objective was to characterize how and not how often movement occurs after rehabilitation training or in everyday free-living environment. We needed to both characterize the quality of the spontaneous movement and measuring the amount/frequency of movement which is pivotal in a stroke unit. Moreover the asymmetry calculation is different because the variation ratio $[9,10]$, being a ratio between standard deviations of the mean accelerations of the arms, describes the asymmetry during the overall recording period without considering the time profile of changes of motor activity, as the eigenvector calculation does. Since upper limb movements have a linear and rotational component of acceleration, we have also evaluated the $\mathrm{MA}_{\mathrm{e} 2}$ index which is sensitive to both components although it is much more sensitive to sensor rotations. Our approach was to evaluate both indices in order to verify if both were necessary to properly describe the clinical picture or if one of them was sufficient. From a clinical perspective, Urbin and colleagues evaluated a composite sample of hemorrhagic and ischemic patients in the sub- acute/chronic phase and in an environment different than the intensive care unit, therefore their results cannot directly be transferred to our clinical context.

As expected, after having removed from the actigraphic recordings the epochs relative to the moments when patients were passively mobilized, the correlation between asymmetry indices and the clinical picture as measured by NIHSS scores improves .

\section{Conclusions}

The results of our feasibility study demonstrate that, in the acute phase of ischemic stroke, the asymmetry between upper limbs measured by the actigraphic $\mathrm{AR}_{2 \_24 \mathrm{~h}}$ index correlates with the overall neurological clinical status and with the paretic upper limb motor deficit as measured by NIHSS. Moreover, the $\mathrm{AR}_{2 \_24 \mathrm{~h}}$ index has a very good capability to identify the paretic arm. These findings suggest that the above described index could implement the existing multiparametric monitoring in stroke unit. In this view, a further technological advance, with improvement of energetic efficiency of the accelerometers, could allow a long-lasting recording from the onset of the symptoms to the discharge from the stroke unit, providing a real time evaluation of motor symptoms during the unstable period of the stroke acute phase.

\footnotetext{
Abbreviations

$\mathrm{AR}_{24 h}$ : Asymmetry Rate Index; Cl: Confidence Intervals; ICC: intra-class correlation coefficient; $M_{\mathrm{e} 1}$ : Epoch-related Motor Activity index; $\mathrm{MA}_{\mathrm{e} 2}$ : Epoch-related Motor Activity index 2; NIHSS: National Institutes of Health Stroke Scale; PIM: Proportional Integrating Measure
}

Acknowledgements

Not applicable. 


\section{Authors' contributions}

Cl: Concept and design, acquisition of data, analysis and interpretation of data, preparation of manuscript; PC: Concept and design, analysis and interpretation of data, preparation of manuscript; MR: Concept and design; analysis and interpretation of data, preparation of manuscript; LP: Concept and design, interpretation of data; CS: Acquisition of data; GR: Acquisition of data, interpretation of data, preparation of manuscript; MF: Concept and design, interpretation of data, preparation of manuscript; PMR: Concept and design, preparation of manuscript. All authors read and approved the final manuscript.

\section{Funding}

This research did not receive any specific grant from funding agencies in the public, commercial, or notfor-profit sectors. This project was partially funded by the Italian Ministry of Health (ricerca corrente).

\section{Availability of data and materials}

The dataset used and/or analyzed during the current study available from the corresponding author on reasonable request.

\section{Ethics approval and consent to participate}

The present study was approved by the institutional ethics committee (Fondazione Policlinico Universitario A. Gemelli, Prot N. 0007987/17). All participants provided written informed consent in accordance with ethical guidelines.

\section{Consent for publication}

All authors have approved the manuscript for publication.

\section{Competing interests}

The authors declare that they have no competing interests.

\section{Author details}

IIRCCS Fondazione Don Carlo Gnocchi, Milan, Italy. ${ }^{2}$ Complex Operative Unit of Neurology, Fondazione Policlinico Universitario A. Gemelli IRCSS, L.go F. Vito, 1, 00168 Rome, Italy. ${ }^{3}$ Department of Geriatrics Neurosciences and Orthopaedics, Università Cattolica del Sacro Cuore, Rome, Italy. ${ }^{4}$ Institute of Neurology, Department Geriatrics, Neuroscience \& Orthopedics, Catholic University, Policlinic A. Gemelli, Rome, Italy.

\section{Received: 6 May 2019 Accepted: 2 October 2019}

Published online: 04 December 2019

\section{References}

1. Keith RA, Wilson DB, Gutierrez P. Acute and subacute rehabilitation for stroke: a comparison. Arch Phys Med Rehabil. 1995;76:495-500.

2. Samsa GP, Matchar DB. How strong is the relationship between functional status and quality of life among persons with stroke? J Rehabil Res Dev. 2004:41:279-82.

3. Dobkin BH. Rehabilitation after stroke. N Engl J Med. 2005;352:1677-84.

4. Hsu HY, Ke CW, Kuan TS, Yang HC, Tsai CL, Kuo LC. Impacts of sensation, perception and motor abilities of the Ipsilesional upper limb on hand functions in unilateral stroke: quantifications from biomechanical and functional perspectives. PM R. 2018:10:146-53.

5. Wattchow KA, McDonnell MN, Hillier SL. Rehabilitation interventions for upper limb function in the first four weeks following stroke: a systematic review and meta-analysis of the evidence. Arch Phys Med Rehabil. 2018;99: 367-82.

6. Kazenwadel J, Pollmacher T, Trenkwalder C, Oertel WH, Kohnen R, Künzel M, Krüger HP. New actigraphic assessment method for periodic leg movements (PLM). Sleep. 1995;18:689-97.

7. van Hilten JJ, Middelkoop HA, Kerkhof GA, Roos RA. A new approach in the assessment of motor activity in Parkinson's disease. J Neurol Neurosurg Psychiatry. 1991;54:976-9.

8. Bochniewicz EM, Emmer G, McLeod A, Barth J, Dromerick AW, Lum P. Measuring functional arm movement after stroke using a single wrist-worn sensor and machine learning. J Stroke Cerebrovasc Dis. 2017:26:2880-7.

9. Urbin MA, Waddel KJ, Lang CE. Acceleration metrics are responsive to change in upper extremity function of stroke survivors. Arch Phys Med Rehabil. 2015;96:854-61.
10. Urbin MA, Bailey RR, Lang CE. Validity of body-worn sensor acceleration metrics to index upper extremity function in hemiparetic stroke. J Neurol Phys Ther. 2015;39:111-8.

11. Rand D, Eng JJ. Disparity between functional recovery and daily use of the upper and lower extremities during subacute stroke rehabilitation. Neurorehabil Neural Repair. 2012;26:76-84.

12. Lang CE, Wagner JM, Edwards DF, Dromerick AW. Upper extremity use in people with hemiparesis in the first few weeks after stroke. J Neurol Phys Ther. 2007;31:56-63.

13. Rand D, Eng JJ. Predicting daily use of the affected upper extremity 1 year after stroke. J Stroke Cerebrovasc Dis. 2015;24:274-83.

14. Hayward KS, Eng JJ, Boyd LA, Lakhani B, Bernhardt J, Lang CE. Exploring the role of accelerometers in the measurement of real world upper-limb use after stroke. Brain Impairment. 2016;17:16-33.

15. Page SJ, Sisto S, Johnston MV, Levine P. Modified constraint-induced therapy after subacute stroke: a preliminary study. Neurorehabil Neural Repair. 2002;16:290-5.

16. Gubbi J, Rao AS, Fang K, Yan B, Palaniswami M. Motor recovery monitoring using acceleration measurements in post acute stroke patients. Biomed Eng Online. 2013:16:12-33.

17. Goldstein LB, Bertels C, Davis JN. Interrater reliability of the NIH stroke scale. Arch Neurol. 1988:46:660-2.

18. Le Heron C, Fang K, Gubbi J, Churilov L, Palaniswami M, Davis S, Yan B. Wireless accelerometry is feasible in acute monitoring of upper limb motor recovery after ischemic stroke. Cerebrovasc Dis. 2014;37:336-41.

19. Reiterer V, Sauter C, Klösch G, Lalouschek W, Zeitlhofer J. Actigraphy- a useful tool for motor activity monitoring in stroke patients. Eur Neurol. 2008; 60:285-91.

20. Rabuffetti M, Meriggi P, Pagliari C, Bartolomeo P, Ferrarin M. Differential actigraphy for monitoring asymmetry in upper limb motor activities. Physiol Meas. 2016;37:1798-812

21. Pexman JH, Barber PA, Hill MD, Sevick RJ, Demchuk AM, Hudon ME, Hu WY Buchan AM. Use of the Alberta stroke program early CT score (ASPECTS) for assessing $C T$ scans in patients with acute stroke. AJNR Am J Neuroradiol. 2001:22:1534-42.

22. Oldfield RC. The assessment and analysis of handedness: the Edinburgh inventory. Neuropsychologia. 1971:9:97-113.

23. Lehnkering H, Strauss A, Wegner B, Siegmund R. Actigraphic investigations on the activity rest behavior of right- and left-handed students. Chronobiol Int. 2006;23:593-605.

24. Nagels G, Mariön P, Pickut BA, Timmermans L, De Deyn PP. Actigraphic evaluation of handedness. Electroencephalogr Clin Neurophysiol. 1996;101: 226-32.

25. Gebruers N, Truijen S, Engelborghs S, Nagels G, Brouns R, De Deyn PP. Actigraphic measurement of motor deficits in acute ischemic stroke. Cerebrovasc Dis. 2008;26:533-40.

26. Gebruers N, Truijen S, Engelborghs S, De Deyn PP. Predictive value of upper-limb accelerometry in acute stroke with hemiparesis. J Rehabil Res Dev. 2013;50:1099-106

27. Gebruers N, Truijen S, Engelborghs S, De Deyn PP. Prediction of upper limb recovery, general disability, and rehabilitation status by activity measurements assessed by accelerometers or the Fugl-Meyer score in acute stroke. Am J Phys Med Rehabil. 2014;93:245-52.

\section{Publisher's Note}

Springer Nature remains neutral with regard to jurisdictional claims in published maps and institutional affiliations.

Ready to submit your research? Choose BMC and benefit from:

- fast, convenient online submission

- thorough peer review by experienced researchers in your field

- rapid publication on acceptance

- support for research data, including large and complex data types

- gold Open Access which fosters wider collaboration and increased citations

- maximum visibility for your research: over 100M website views per year

At $\mathrm{BMC}$, research is always in progress.

Learn more biomedcentral.com/submission 